\title{
Botulinum Toxin and Fillers for Maxillofacial Esthetics
}

\author{
Sainath Matsa
}

\subsection{Introduction}

\subsubsection{Facial Aesthetics}

The field of cosmetology has steadily progressed over the past decade, and cosmetic procedures are moving towards a new era [1]. People are becoming more aware of the way they look, especially the face and are turning to medical and dental professionals to improve their appearance. Attractive facial aesthetics at any age has social and psychological benefits. Facial skin constitutes a major part in contributing to facial aesthetics. The skin is a reflection of several body characteristics, of which gender is a prominent one [1]. Age, genetic, hormonal and exogenous factors can affect both skin structure and function and are responsible for differences between different men and women. This chapter gives the basics and advances in the field of facial cosmetic and functional correction using Neurotoxins (Botulinum toxin) and Dermal Fillers.

\subsubsection{Facial Skin Physiology, Muscular Anatomy and Mechanical Properties}

In humans, skin including the epidermis and dermis is 1.428 times thicker in men than in women across 5-90 years of age [1]. However, women tend to have thicker subcutaneous fat. It has been found that, in men, it gradually becomes thinner with advancing age (12-93 years), whereas in women, the

Electronic Supplementary Material The online version of this chapter (https://doi.org/10.1007/978-981-15-1346-6_33) contains supplementary material, which is available to authorized users.

S. Matsa $(\bowtie)$

Praseedha Clinic for Maxillofacial Cosmetic Surgery,

Chennai, Tamil Nadu, India skin thickness remains constant till the fifth decade, after which it tends to decrease [2].

Gender plays an important role in facial wrinkling. In men, the incidence of forehead wrinkles is higher than in women. However, the incidence of upper eyelid wrinkles does not appear to be influenced by gender. Wrinkles in other parts of the face are found to be greater in men than in women, except above 65 years of age, when the incidence appears to equalise [3]. One study evaluated the skin morphology, elasticity and areas of sagging using photographs and a cutometer. The authors found that these were similar in both genders in the cheek region, but in the lower eyelids, sagging was more severe in males after middle age $[4,5]$.

\subsubsection{Facial Muscles and Their Actions} (Fig. 33.1)

A good understanding of the action of the various facial muscles is important for precise application of botulinum toxin. The muscles and their actions are tabulated (Table 33.1).

\subsection{Botulinum Toxin}

\subsubsection{Botulinum Toxin-Type A}

Botulinum Toxin type A was first used on the face by Carruthers and Carruthers in the late 1980s [6]. Following studies in the 1990s about its cosmetic use, botulinum toxin was approved by the USA Food and Drug Administration (FDA). This led to a revolution in treating ageing skin in recent years [1]. 
Fig. 33.1 Muscles of facial expression

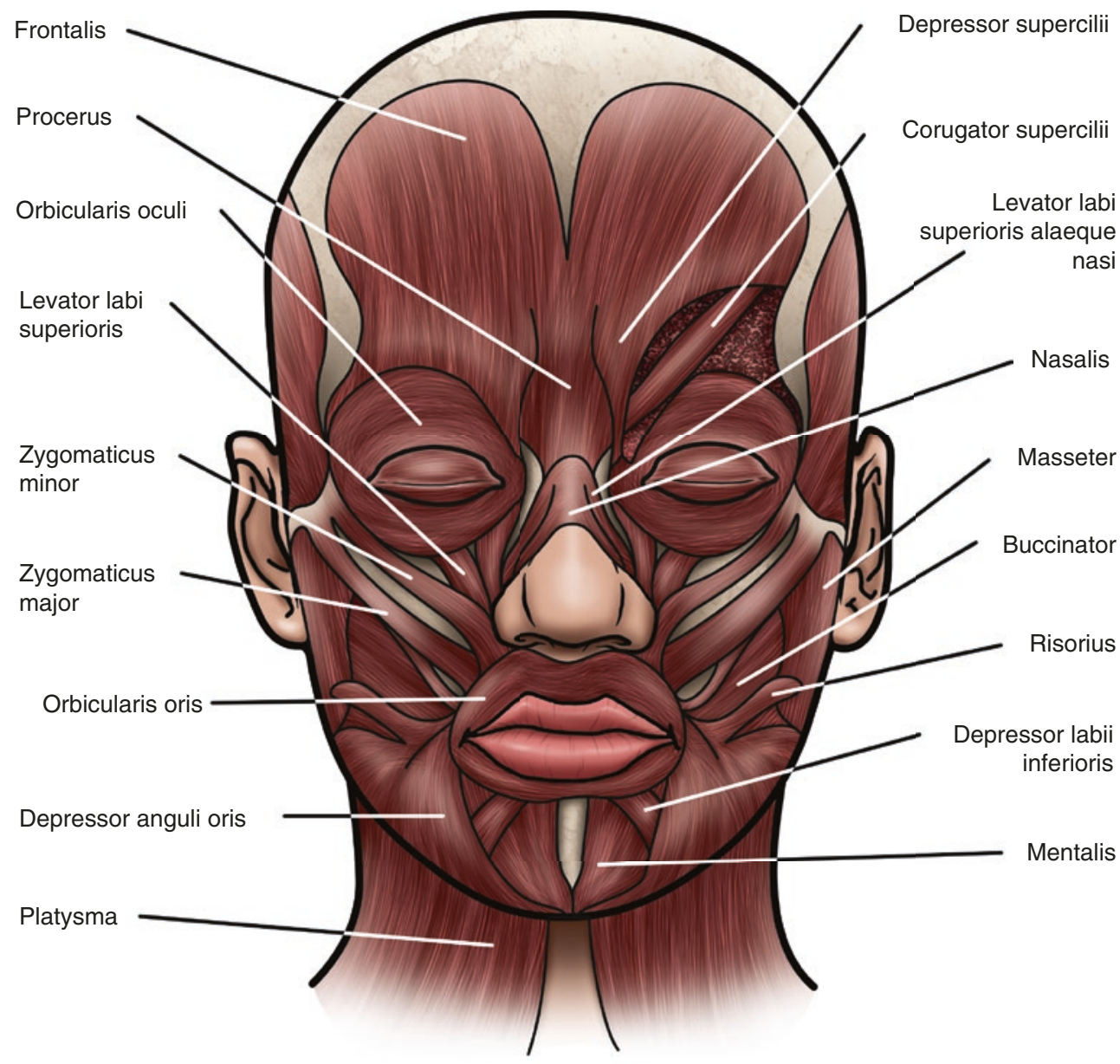

CAssociation of Oral and Maxillofacial Surgeons of India
Table 33.1 Facial Muscles and Their Actions

Frontalis-Raising the eyebrows; transverse wrinkling of the forehead

Corrugator-Vertical/oblique wrinkling of the forehead; draws the eyebrows together

Procerus-Pulls the glabellar skin in an inferior direction and causes transverse wrinkles

Depressor Supercilii-Pulls the eyebrow downwards on the medial canthal region

Orbicularis Oculi-Controls the sphincter of the eye Risorius-Lateral movement of the corner of the mouth Orbicularis Oris-Opening and closing of the mouth (sphincter action)

Levator Labii Superioris-Pulls the upper lip superiorly Depressor Anguli Oris-Draws the corner of the mouth inferiorly Depressor Labii Inferioris-Pulls the lower lip downwards Modiolus - It's a union of muscles, situated lateral to the external commissure of the mouth, allowing symmetrical perioral expression.

\subsubsection{Pharmacology and Mechanism of Action}

Clostridium botulinum produces an exotoxin. It is an anaerobic gram positive bacillus (Fig. 33.2) which forms spores. It has eight types of strains which are labelled alphabetically: A, B, C, D, E, F, G, and H [7].

Two types of strains, A and B, are available currently. These result from the modification of the protein structure that has been used for a variety of medical and cosmetic purpose. Botulinum Neurotoxin causes denervation of the motor neuron temporarily, in the treated muscle and selectively inactivates the nerve terminals by blocking the release of acetylcholine and the target protein SNAP25, [8] leading to a temporary and reversible blockade of cholinergic transmission. In the neuromuscular junction, the blockade of the release of acetylcholine promotes muscle relaxation to muscular palsy [9] (Fig. 33.3a, b, c).

\section{Reconstitution, Dilution and Dose:}

Botulinum Toxin Type-A is available as lyophilised powder that must be stored frozen $-4{ }^{\circ} \mathrm{C}$ or lower. Reconstitution of the powder may be done using $0.9 \%$ Normal Saline solution, which is isotonic. Once reconstituted, the solution must be used within 4-8 h, after which the potency of the drug may be lost, and contamination of the vials may occur. 


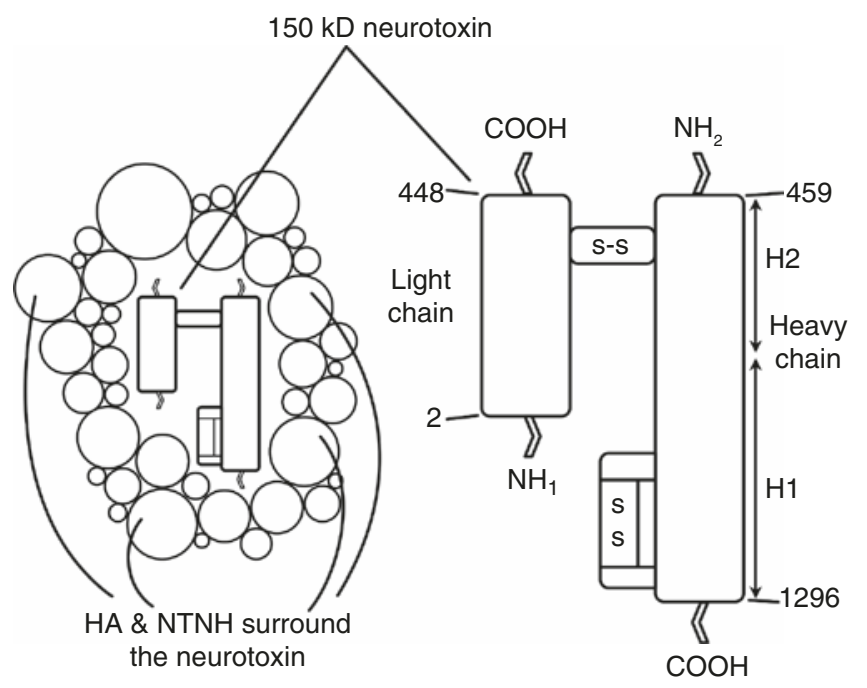

900kD BoNT/A complex contains:

- $150 \mathrm{kD}$ neurotoxin

- Hemagglutanins (HA)

- Nontoxic, non-HA proteins (NTNH)

CAssociation of Oral and Maxillofacial Surgeons of India

Fig. 33.2 Chemical structure

- Botulinum toxin A is marketed in two vials-50 and $100 \mathrm{U}$.

- In mice, the Median Lethal Dose is $1 \mathrm{U}$. The MLD in humans is estimated at $3000 \mathrm{U}$.

- For reconstituting $100 \mathrm{U}, 2.5 \mathrm{ml}$ of $0.9 \%$ Normal Saline may be used, which gives a concentration of $40 \mathrm{U} / \mathrm{ml}$.

Many commercial brands are available for Botulinum Neurotoxin-A, like Siax ${ }^{\circledR}$, Botox ${ }^{\circledR}$, Xeomin $^{\circledR}$ and Dysport ${ }^{\circledR}$ and every brand has variation in its dilution.

\subsubsection{Indications}

Botulinum toxin injections may be used in the clinical scenarios highlighted in Box 33.1.

Box 33.1 Indications of Botulinum Toxin

- Wrinkling of the face

- Facial rejuvenation of ageing face

- Gingival smile

- Masseteric hypertrophy

- Facial asymmetry

- Platysmal wrinkling and bands

- Hyperhidrotic conditions (excessive sweating)

- Blepharospasm

- Spasmodic torticollis

- Dystonia

- cranial, lower facial, cervical, oromandibular.

\subsubsection{Contraindications [10]}

The use of Botulinum toxin injections is contraindicated in the following clinical situations:

- Pregnancy and breastfeeding.

- Individuals with an infection in the proposed area of the injection.

- Neuromuscular transmission disorders (myasthenia gravis).

- Individuals under medications that may influence neuromuscular transmission. These include Calcium channel blockers, Penicillamine, Quinine, Aminoglycosides, Pancuronium, Tubocurarine and Succinylcholine.

- Individuals under medications that interfere with coagulation like Acetylsalicylic Acid, Anticoagulants and Vitamin E.

\section{Patient Selection:}

In the present era, patients have increased awareness and knowledge about their health and skin conditions. They may be very ambitious and optimistic about the procedure and are likely to expect a high level of satisfaction with their personal appearance after the treatment. The goal of treatment is to achieve a better looking and natural appearance. The patients' psychological aspects and expectations should be understood and evaluated prior to the start of any cosmetic treatment.

\subsubsection{Injection Techniques (Video 33.1)}

The following techniques are used for injecting botulinum toxin into various areas of the face.

(a) Glabellar lines injection technique (Fig. 33.4a, b): Visualise an imaginary " $X$ " formed by two lines that join the inner brows with the contralateral inner canthus [11]. The injection must be given at the midpoint of the ' $\mathrm{X}$ '. Conventionally, the Corrugator Supercilii muscle is visualised by observing the medial part of the eyebrow when the patient frowns. Botulinum Toxin is then slowly injected into the belly [11] of the muscle on either side. The needle must be maintained at $0.5 \mathrm{~cm}$ from the upper orbital rim, and lie internal to the mid-pupillary line. The total dose for glabellar line ranges from 10 to $15 \mathrm{U}$ and can be increased to a maximum of $40 \mathrm{U}$ based on the severity of the wrinkles.

(b) Forehead lines Injection technique (Fig. 33.5): The frontalis muscle is superficial and may be easily identified by asking the patient to raise and lower the brow. The extent of muscle movement is then assessed. Injections must be done in the superficial subcutaneous tissue, over the entire forehead from medial to lateral. The typical dose ranges from 2 to $3 \mathrm{U}$ in each point of small dots represented on the upper and lower aspects of the forehead or 
a

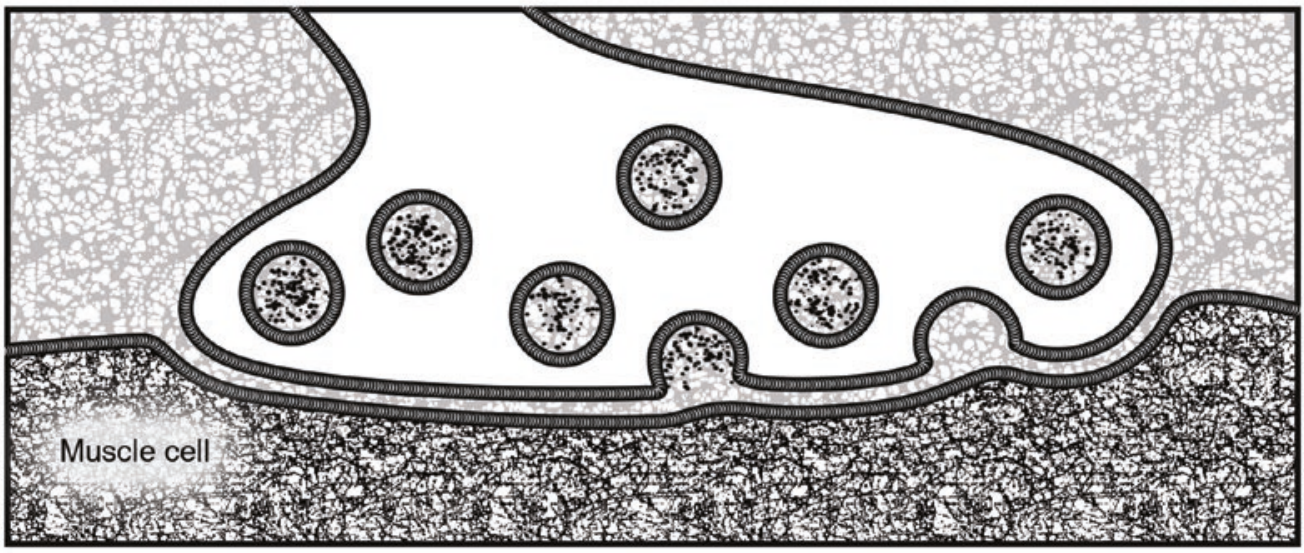

b

\section{Normal transmitter release}

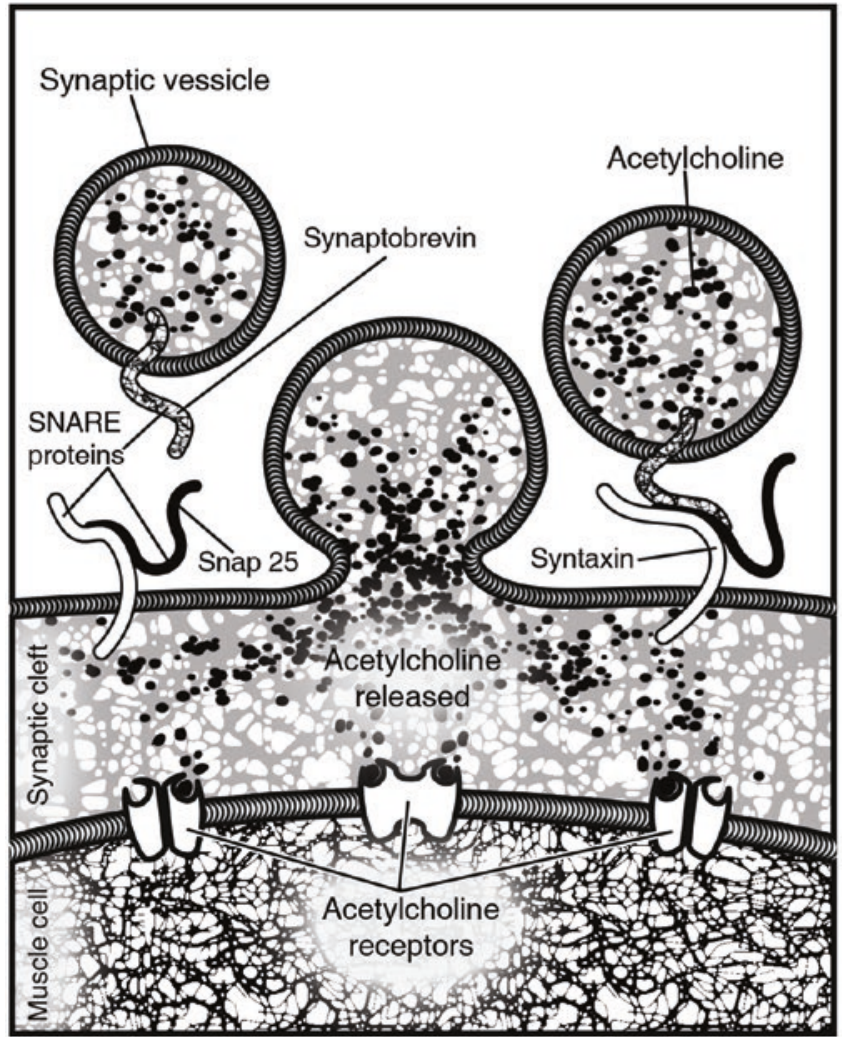

(C)Association of Oral and Maxillofacial Surgeons of India

Fig. $33.3(\mathbf{a}-\mathbf{c})$ Action at the neuromuscular junction

$5 \mathrm{U}$ per point of the middle aspect of the muscle, represented in a big dots as given below in the figure. Frontal injections and glabellar injections must preferably be done together, to avoid increased compensatory use of glabellar muscle, which are mainly depressors $[12,13]$. The dose of the injections must be kept small enough to just weaken the muscle instead of producing total paral-
C

\section{Action of botulinum toxin $\mathrm{A}$}

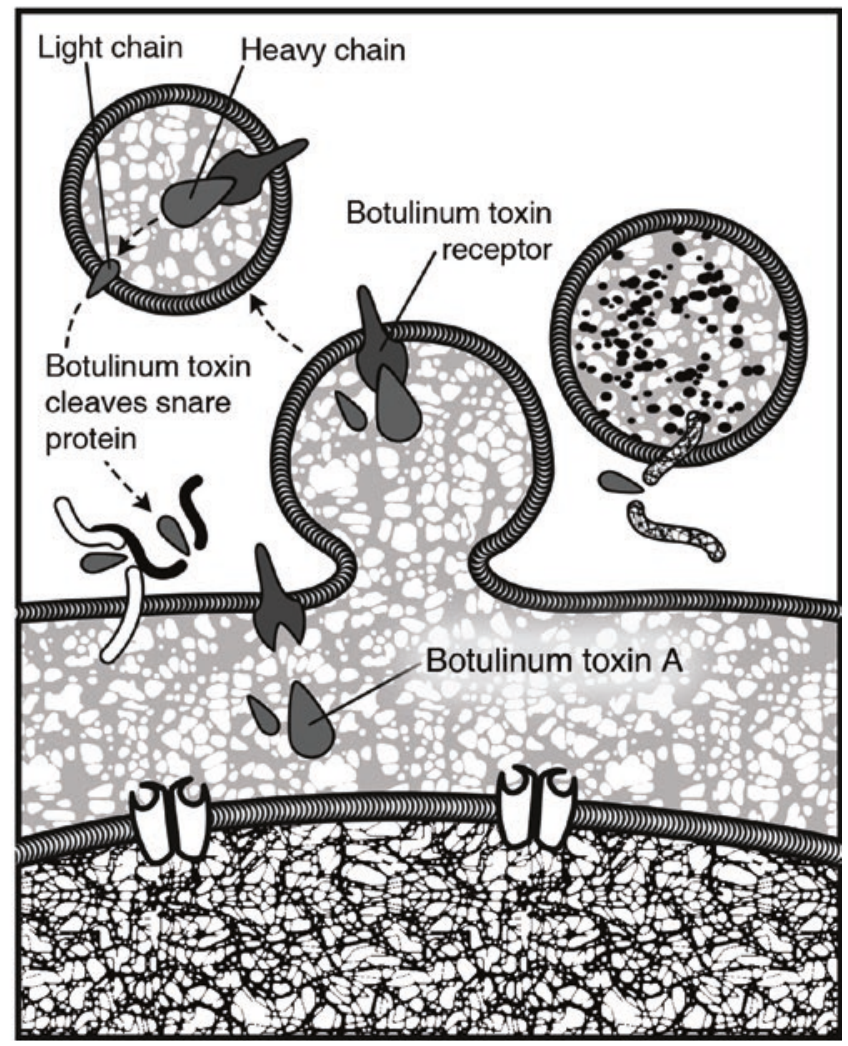

ysis. This is because the frontalis is responsible for facial expressiveness, and total paralysis would cause brow ptosis $[14,15]$. It is also important to preserve at least some frontal is muscle movement, responsible for facial expression and lift of the eyelids and brows.

(c) Crow feet wrinkles Injection technique (Fig. 33.6a, b): Three to four injections of Botulinum toxin-A may be 
Fig. 33.4 (a, b) Glabellar lines injection technique a

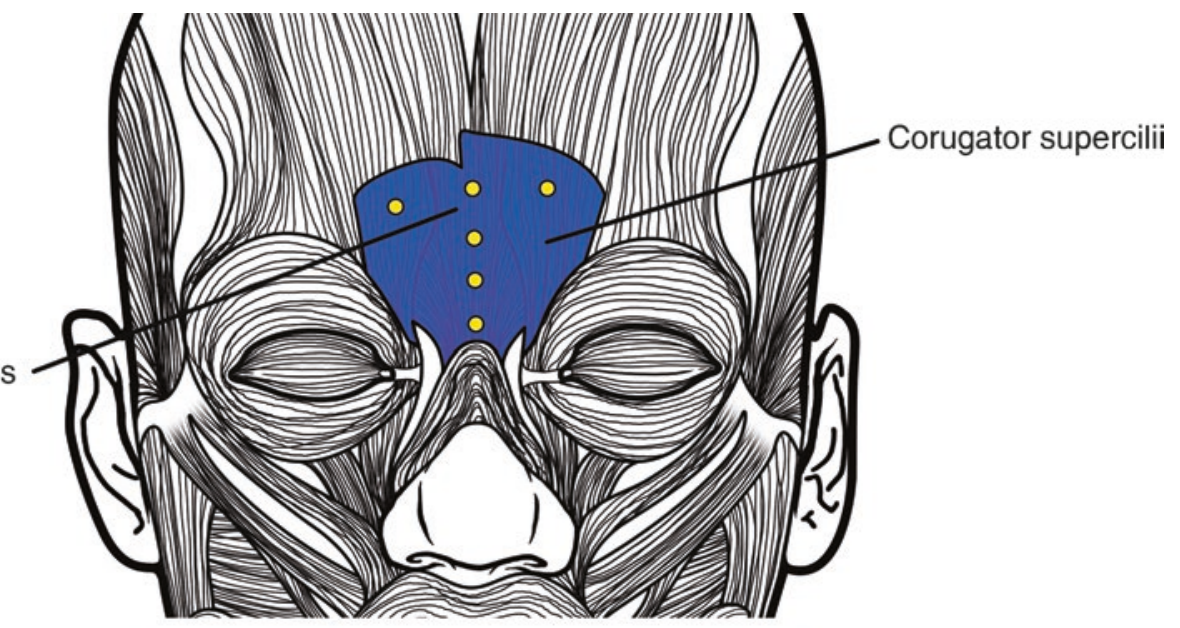

b

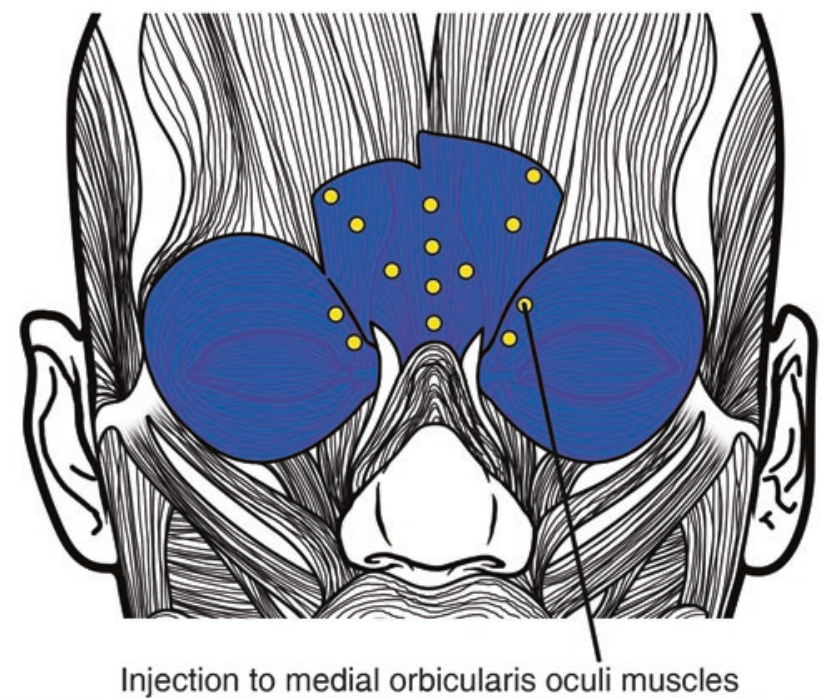

CAssociation of Oral and Maxillofacial Surgeons of India

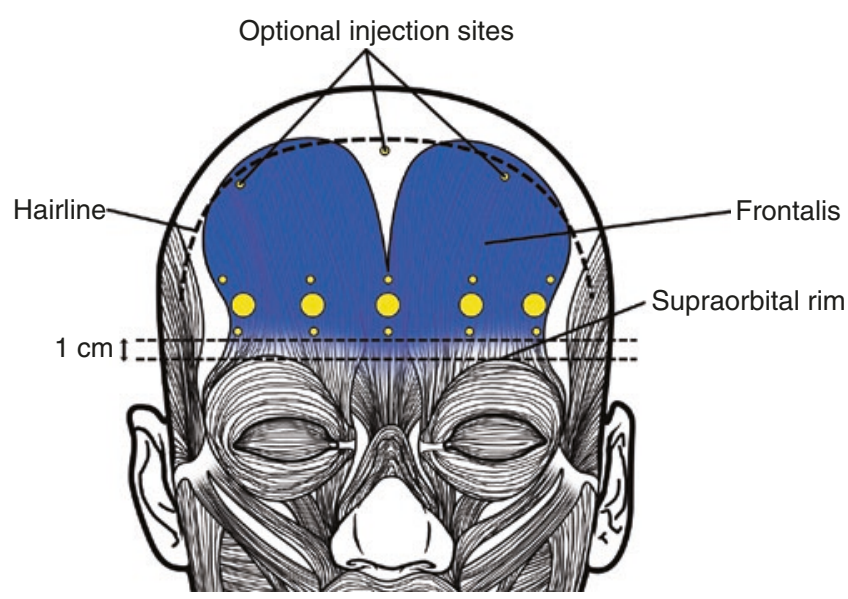

Do not inject within $1 \mathrm{~cm}$ of the supraorbital rim (CAssociation of Oral and Maxillofacial Surgeons of India

Fig. 33.5 Forehead lines injection technique administered lateral to the eye, in the 'crow's feet' region that radiates out from the lateral canthi. Around 8-20 U may be administered on each side [16]. The injection must be placed $1 \mathrm{~cm}$ lateral to the orbital rim and must be above the canthal angle, to avoid upper lateral lag. To achieve this, one can place a guiding finger of the other hand at the lateral orbital rim. Owing to the superficial location of the muscle, the needle need not be advanced deep into the subcutaneous tissue. Botulinum Toxin has a wide zone of effect, and therefore a superficial dermal injection will minimise bruising, but will still give good clinical results [16].

(d) Elevating Oral commissures and Smile line Injection technique (Fig. 33.7): Depressor anguli oris is the muscle to be elevated for improving the smile lines. It is indicated in patients with inverted smile line (reverse smile line), which is caused by pulling the corner of the mouth inferiorly. To identify the depressor anguli oris muscle, the patient must frown and the muscle must be simultaneously palpated $1 \mathrm{~cm}$ lateral and inferior to the oral 


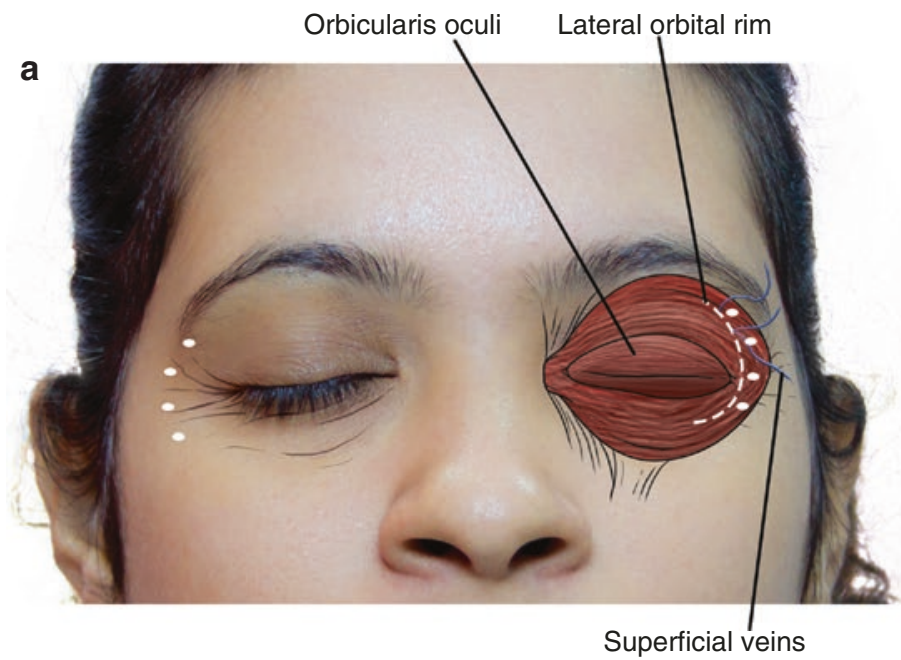

CAssociation of Oral and Maxillofacial Surgeons of India

Fig. 33.6 (a, b) Crow feet wrinkles injection technique

commissure. Inject approximately $2-5 \mathrm{U}$ deeply into the muscle on either side [16].

(e) Gummy smile or Gingival show correction Injection technique (Fig. 33.8): In some patients, while smiling, their upper lip is pulled up, which reveals some amount of gingival tissue. If this is $>1 \mathrm{~cm}$, it is referred to as a "Gummy smile or Gingival Show". The levator labii superioris alaeque nasi elevates the upper lip during smile. These muscles have their origin on the frontal process of the maxilla, and insert into the skin of the lateral aspect of the nose and upper lip. If only one muscle contracts, it results in a 'snarl', and this muscle has been referred to as the "Elvis" muscle [16]. Normally, 1-2 $U$ of the Botulinum neurotoxin is injected on each side in the muscle. Care should be taken because this injection can produce elongation of the upper lip.

(f) Platysmal wrinkles Injection technique (Fig. 33.9): The platysma forms horizontal lines or wrinkles. Into every horizontal crease, an intradermal injection of 1-2 U may be injected for every $1.0-1.5 \mathrm{~cm}$ [16]. There may be several creases, but each treatment session must not use more than 15-20 U. In these areas, careful injections are absolutely essential, as these muscles are cholinergic, and deep injections may affect swallowing. If the injections are placed at deeper levels, or high volumes are used, a weak or diminished swallow may result.

(g) Masseteric Hypertrophy Injection technique (Fig. 33.10): The masseter can give masculine characteristics, such as square jawlines and wide mandibular borders. This is enhanced when the muscle hypertrophies, and may not be attractive in women. Bruxism and clenching of teeth can lead to hypertrophy of the masseter muscle, which in turn increases the horizontal width of the mandible [16]. While injecting into the masseter, one finger may be
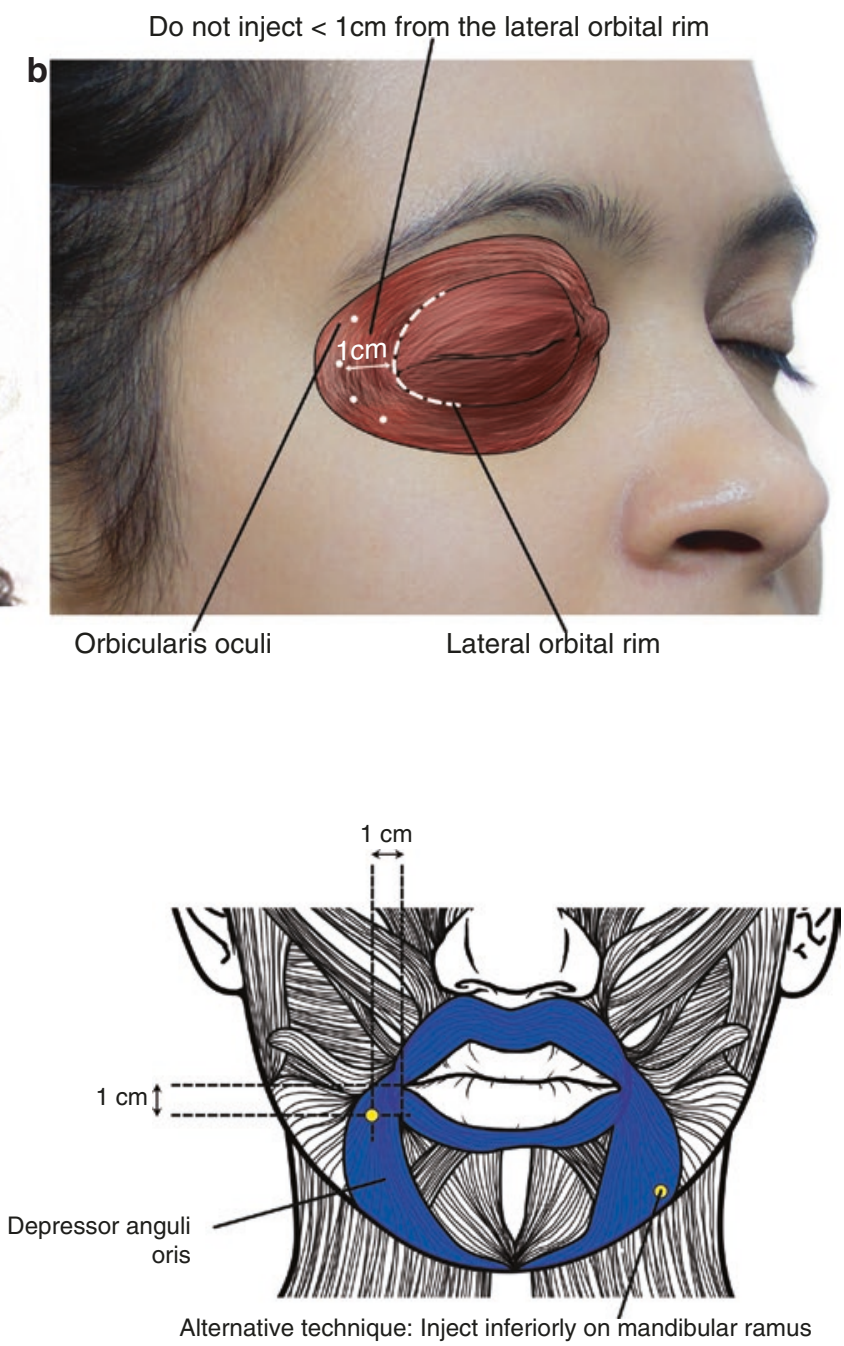

CAssociation of Oral and Maxillofacial Surgeons of India

Fig. 33.7 Smile line correction

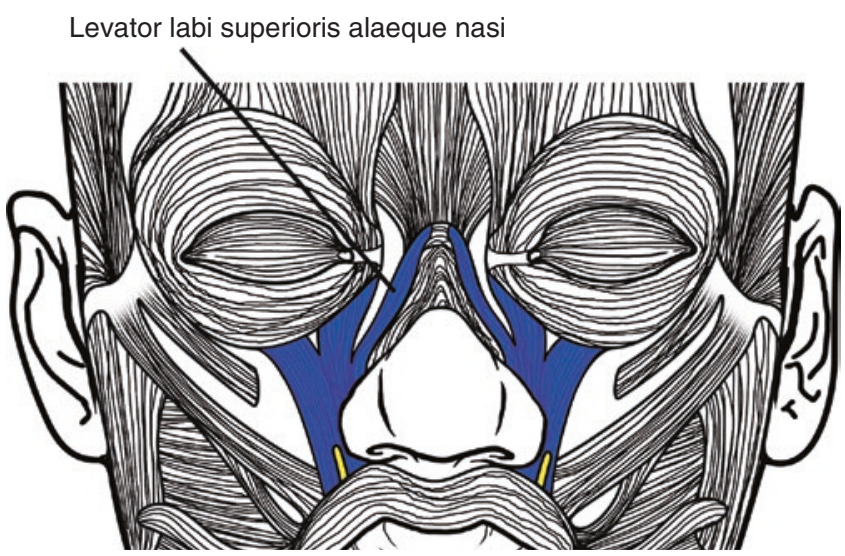

(C)Association of Oral and Maxillofacial Surgeons of India

Fig. 33.8 Gummy smile correction

placed along the lower border of the mandible, one finger along the posterior border and one at mandibular angle. This may be done with the patient clenching, as 


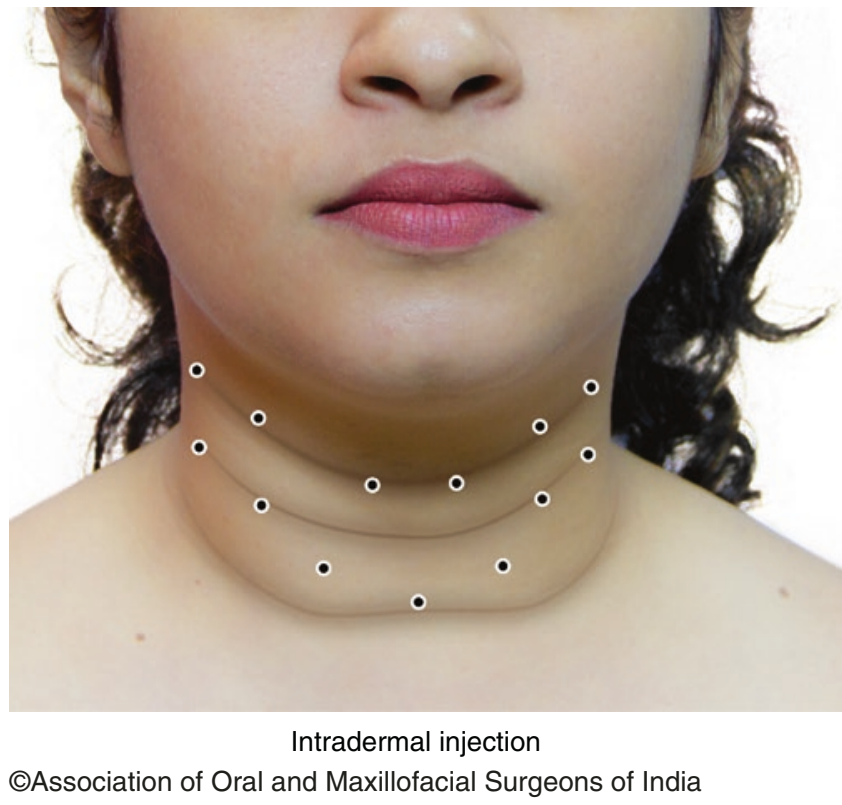

Fig. 33.9 Platysmal banding

this marks the perimeter of the muscle. While injecting bone should be felt by the needle and withdrawn slightly just above the bone and deposit 4-5 $\mathrm{U}$ along the marked lines. Depending on the volume of hypertrophy, around $20 \mathrm{U}$ may be injected [16]. Over-injection at the masseter region may result in problems with bite or chewing.

(h) Frey's Syndrome or Gustatory sweating Injection Technique (Fig. 33.11): This is a condition in which mild to profuse sweating occurs in the cheek or malar area while eating. A diagnostic test called "starch-iodine test" [16] can be performed prior to injection of Botulinum toxin. Povidone iodine is applied over the cheek and corn starch is sprinkled. The patient is advised to eat, to stimulate the salivary gland and left to dry for a few minutes. The corn starch turns black in the area of sweating [16], and a grid is drawn along this area. Once the test is confirmed, usually $30-50 \mathrm{U}$ is injected along the grid as shown. The botulinum toxin blocks acetylcholine, which is the neurotransmitter that stimulates sweating.

\subsubsection{Complications and Recommendations While Using Botulinum Toxin}

- Apply pressure at the site before and after treatment. Cold packs may also be used.

- The use of small syringes and fine-gauge $(30 \mathrm{~g})$ needles can reduce pain and bruising at the injected site.

- Using topical anaesthesia (EMLA-Eutectic Mixture of Local Anaesthesia) reduces pain while injecting.

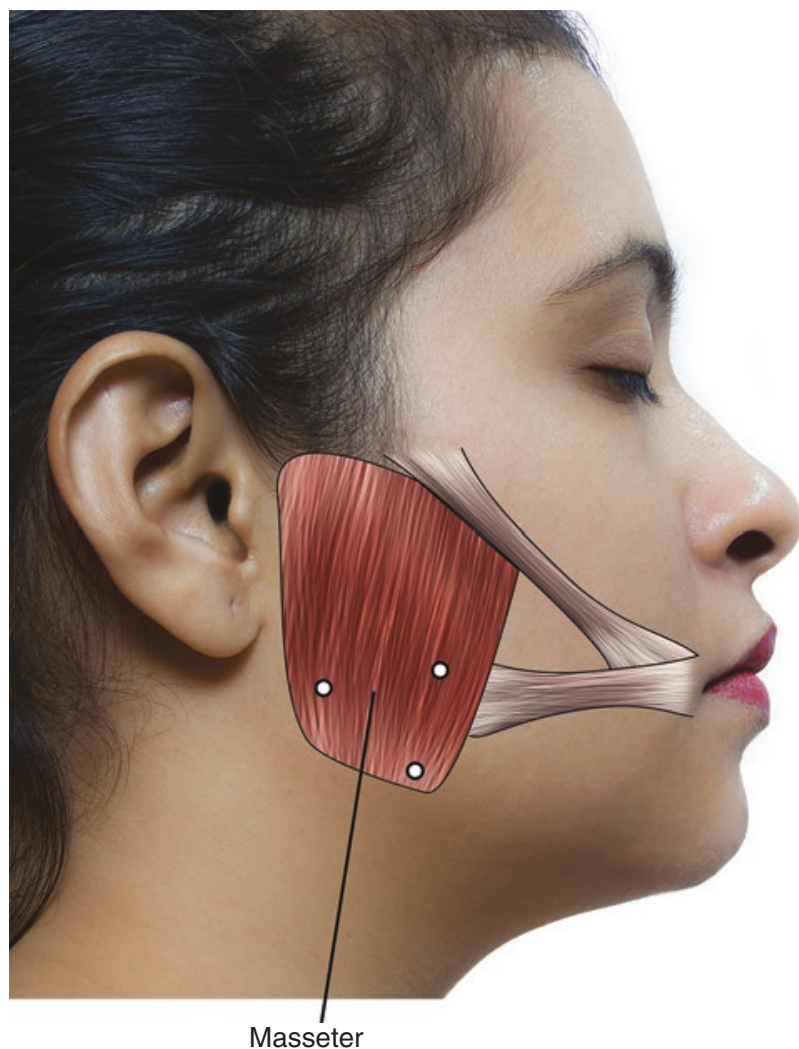

CAssociation of Oral and Maxillofacial Surgeons of India

Fig. 33.10 Masseteric hypertrophy

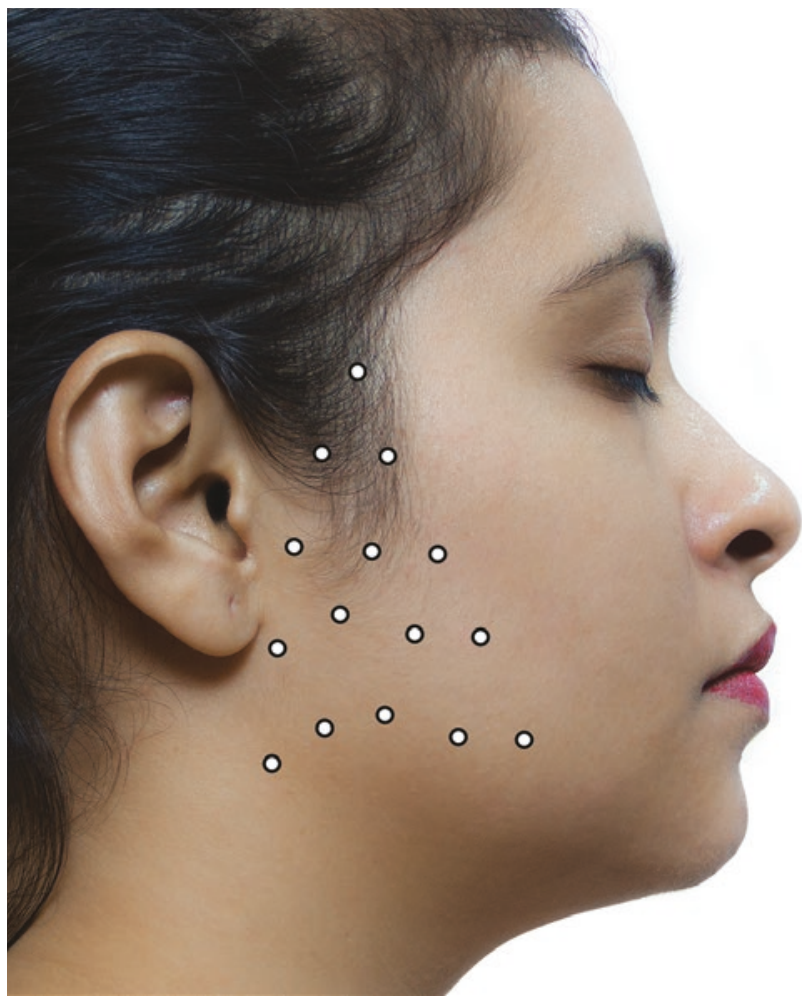

CAssociation of Oral and Maxillofacial Surgeons of India

Fig.33.11 Frey's Syndrome 
- Injections should be symmetrical regarding doses, muscles and areas. This is important for the natural balance of the facial structures and to avoid asymmetries.

- Since the results are expected for 4-6 months, treatments are usually repeated twice a year, for maintenance of the results.

- There are isolated few reports of systemic adverse effects after injections with the use of doses larger than those usually recommended for cosmetic purposes [17].

- The most common injection-related side effects are pain, transient edema at the injected site, erythema, haematomas and ecchymosis [13, 17].

- Common technique-dependent complications include eyelid ptosis, asymmetries and excessive brow elevation.

- In the lower face, complications are related to high doses can cause undesirable paralysis of the musculature, resulting in asymmetric smiling and complications due to the incompetence of the sphincter function of the mouth.

- In the neck, complications can be dysphagia and difficulty in the movements.

\subsection{Dermal Fillers}

\subsubsection{Role of Fillers in Facial Aesthetics}

Throughout the past decades, there have been major changes and advancements in the injectable preparations used for soft tissue augmentation. Introduced by Dr. Arnold Klein [1] in the 1980s, for lip augmentation, collagen has progressed to the broader concept of volumising the face and to correct the subcutaneous atrophy due to ageing and fat loss.

Following extensive clinical trials in the late 1970s, the FDA first approved the use of bovine collagen in 1981, which greatly advanced the field of soft-tissue augmentation. Over the past 10 years, several types of facial fillers have been approved in the United States and Europe, and there is a constantly evolving and expanding assortment of the dermal filler materials and devices for soft tissue augmentation [18].

Hyaluronic Acid (HA), which was introduced as a facial filler in 2003, brought about a much needed change from the allergies being reported due to bovine collagen [18]. Hyaluronic Acid is a member of the glycosaminoglycan family and a natural component of human connective tissue. The HA molecule is identical across all species and lacks a protein component, thus it has little to no potential for immunologic reaction in humans. It is composed of repeating disaccharide units, stabilised with cross-linked hydroxyl groups that bind water to create volume. This gives a plumped appearance to the skin. HA in the skin decreases with age and sun exposure, reducing the skin's water-binding capacity and turgor, ultimately leading to skin wrinkling and sagging [19]. HA can absorb up to 1000 times its molecular weight of water, and Hyaluronic Acid fillers volumise the face by replacing body Hyaluronic Acid and restoring hydration [5].
Studies have shown that hyaluronic acid requires less injection volume as compared to bovine collagen for optimal cosmetic results, and HA is also found to be more effective at maintaining the cosmetic correction [20,21].

The U.S. Food and Drug Administration (FDA) has now approved various types of Hyaluronic acids, bio-stimulatory products like calcium hydroxyapatite and poly-L lactic acid, as well as polymethylmethacrylate as a substitute for fillers.

Fillers are categorised as permanent, semi-permanent and temporary. The majority of injectable fillers are temporary, lasting from several weeks to several months, although some reportedly last 9-12 months. Many of these processes require ongoing treatment to maintain the desired appearance [22].

\subsubsection{Classification of Fillers}

Based on their duration of action, fillers may be classified as follows:

Temporary (3-12 Months) These are mainly used to replace collagen in the skin, which weakens with age and loses its elasticity. Collagen has three main sources-bovine, porcine and human. Bovine collagen is very similar to the human molecule and is widely used. It only has specific differences in the end peptides (telopeptides), which are removed in processing, leaving a core protein similar to that of a humans [23]. Hyaluronic acid is the most commonly used Filler material of this category.

Semi-Permanent (1-5 Years) Calcium hydroxyapatite is one of the commonest semi-permanent fillers. It creates a stable scaffold for soft tissues to grow. Calcium hydroxylapatite may be injected into the deep dermis, where the microspheres are held in place until they are resorbed and collagen deposition occurs. This results in formation of non-scar-tissue type of collagen, which provides volume in the area under treatment [24].

Permanent ( $>5$ Years) These are mostly synthetic implants, which are made of Polymethylmethacrylate (PMMA) microspheres. PMMA microspheres may be mixed with denatured bovine collagen and lidocaine, and suspended in a phosphatebuffered saline solution. Since PMMA is inert, it is well tolerated by the body and does not induce allergic reactions [25, 26].

\section{Preparation of the Patient before Injection of Fillers:}

The patient's face is washed gently to dry and disinfect the skin. This is done using propanol solution. Since the dermal fillers are very painful while injecting, application of the topical anaesthesia around the area of injection using EMLA (Eutectic Mixture of Local Anaesthesia) for 30-45 min prior or particular branch of Maxillary division or Mandibular division of the trigeminal nerve is anaesthetised using $2 \%$ Lignocaine as a local anaesthetic injection. 
Fig. 33.12 Various patterns in Injection technique
C) Depot

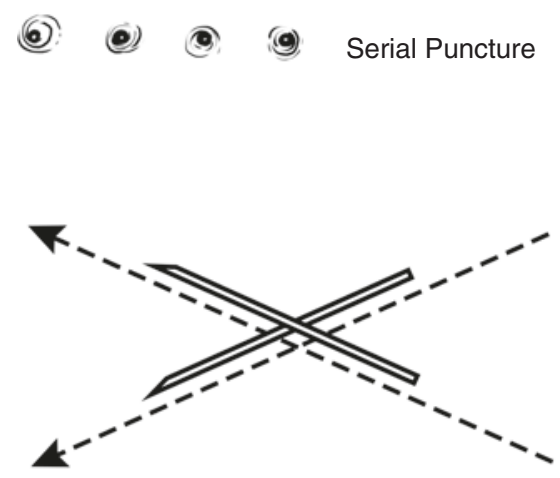

Crosshatching
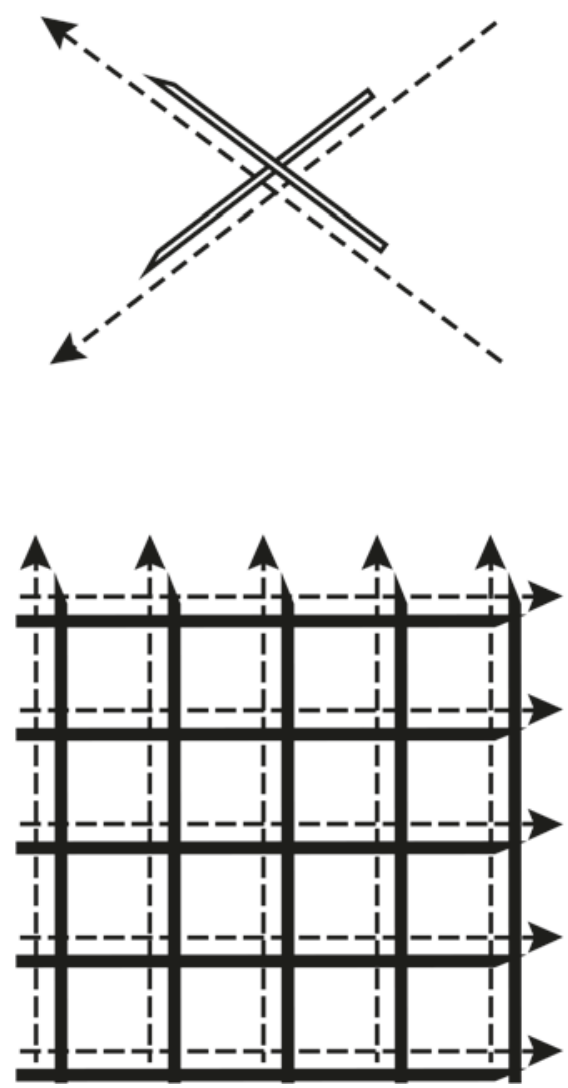

Grid
Anterograde
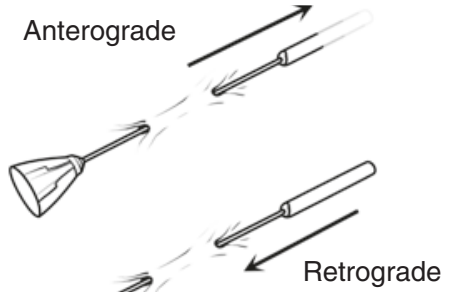

Fanning
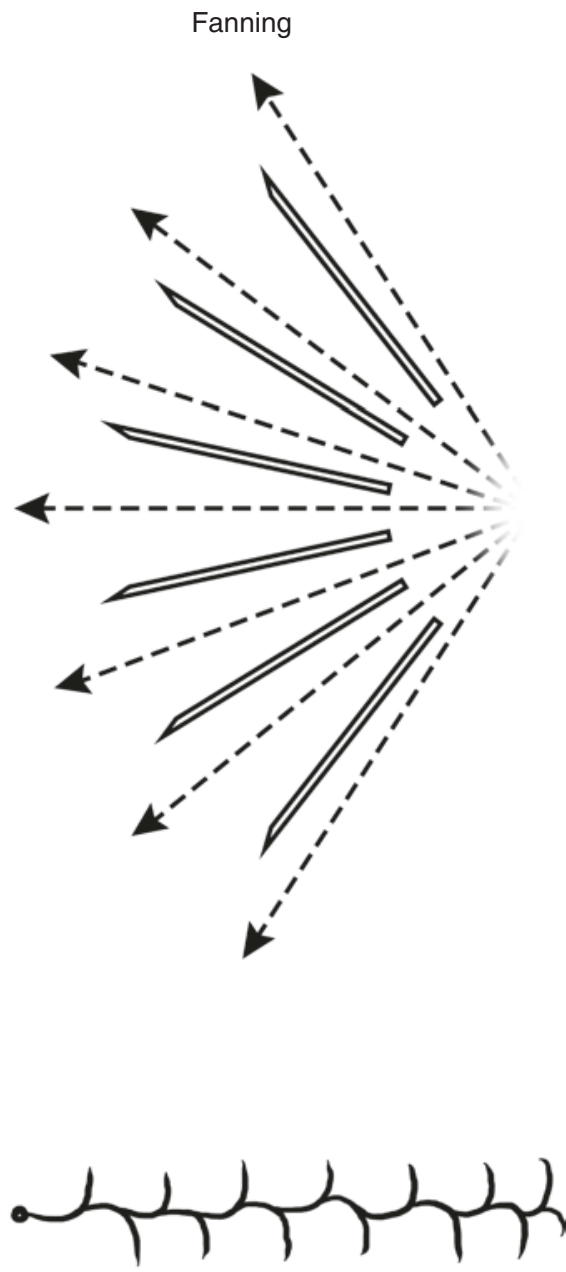

Ferning (retrograde)

CAssociation of Oral and Maxillofacial Surgeons of India

\subsubsection{Dermal Filler Injection Methods (Fig. 33.12)}

Hyaluronic acid is available in syringes in a sterile packed container. These have 26-30 gauge needle, with a length of $1-1 \frac{1}{2}$ inches.

These are injected at the subdermal planes in various fashion which are mentioned in Box 33.2.

The following is a description of various techniques.
Linear Threading: In this technique, fillers are injected in a needle and thread fashion. The needle is inserted and withdrawn repeatedly along a straight line. It has two types.

1. Anterograde Injection: The filler is injected while the needle is being advanced, and the filler is therefore easily tracked in the front of the needle. 


\section{Box 33.2 Dermal Filler Injection Methods}

- Linear threading,

- Depot injection,

- Fanning method,

- Serial puncture,

- Cross hatching,

- Grid and Ferning

2. Retrograde Injection: The filler is not injected simultaneously during needle advancement. Once the needle is slowly withdrawn, the filler is injected.

Depot: In this technique, a small amount of the filler is deposited in the correct plane.

Serial Puncture: In a single wrinkle or fold, multiple closely spaced depot injections are placed.

Fanning: It is done through one point of entry and the needle is rotated like a fan in multiple directions, and the fillers are deposited in a retrograde way. It is important to stop injecting as the needle comes close to the insertion site in order to avoid build-up of fillers at the point of entry.

Cross Hatching: Injecting as multiple linear thread deposited in an X-shaped fashion.

Grid: It is injected as linear threads intersecting perpendicular to each other point of entry.

Ferning: [16] This is similar to retrograde injection. The needle is inserted on either side of the central tract, and the fillers are deposited in a branch-like fashion almost like the branches of a fern.

\subsubsection{Injection Techniques}

(a) Glabellar and Forehead region (Fig. 33.13a,b): The Glabellar region is the most prominent site for wrinkling and very well shown even in a mild expression. There are vertical lines of wrinkling, which result from contraction of the corrugator supercilii muscles, and horizontal lines which occur due to contraction of the procerus muscle. Before injecting, the patient should frown the brow and the needle is inserted at the subdermal plane and injected in a linear fashion and it is also deposited deep and parallel to the wrinkle. Small depots or serial puncture fashion of fillers are injected along the line of the wrinkles throughout its entire length. Gentle

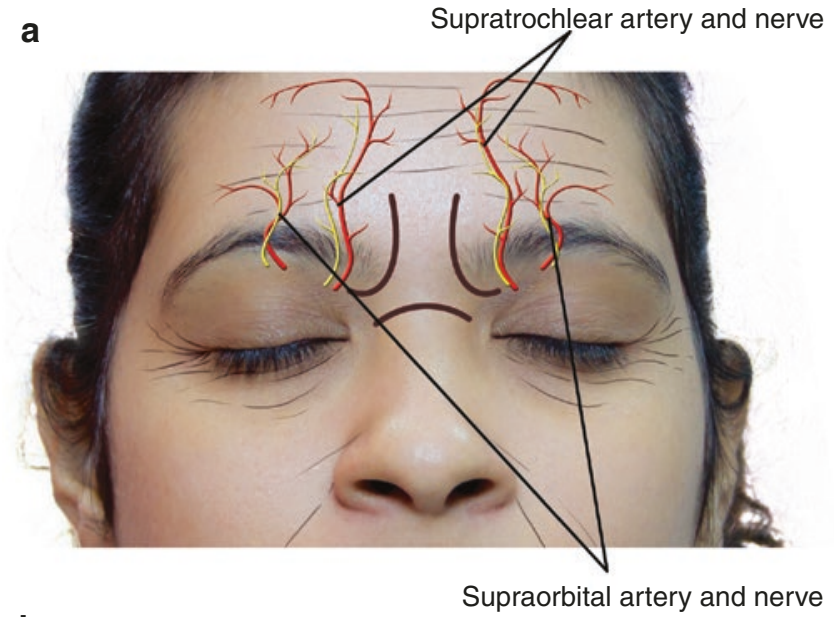

b

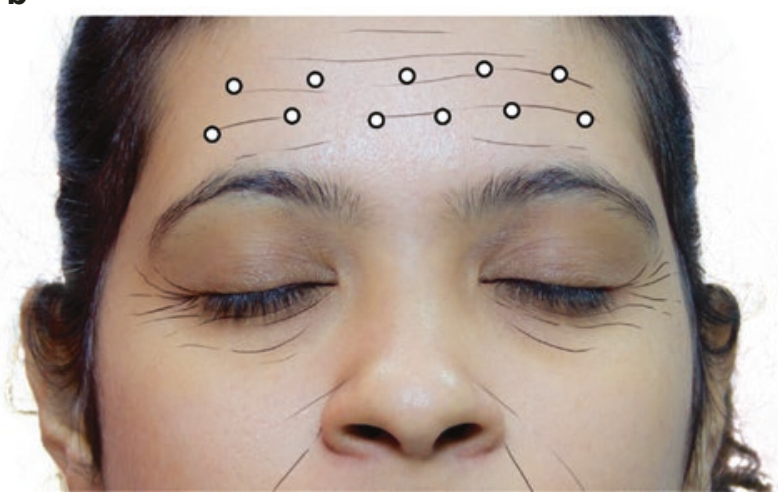

CAssociation of Oral and Maxillofacial Surgeons of India

Fig. 33.13 (a, b) Glabellar \& forehead wrinkles

rub or massaging to be done to distribute the filler uniformly. In the case of bruising, icepacks can be used. Injecting into a vessel must be avoided as this can lead to the formation of emboli.

(b) Nasolabial Fold (Fig. 33.14a,b): The nasolabial fold is defined as the groove from corner of the alar base to the margin lateral to the angle of the mouth. The nasolabial groove must never be eliminated completely as this can result in an unaesthetic appearance. Injection may be done using serial puncture, linear threading, cross-hatching, or fanning. Only the medial part of the fold must be augmented, with injections perpendicular to this. This is best done by imagining a tall, thin, triangular deficit in front of the fold that needs to be filled. To prevent bruising, ice and pressure may be applied. Initially, hyaluronic acid swells and may appear as a firm mass on palpation but gradually blends in after the first week.

(c) Lip Augmentation (Fig. 33.15): This is one of the most common cosmetic procedures done using Hyaluronic acid filler for augmenting or everting the lips. The areas to be augmented are the outline of the lip, body of the lip or both. There is a potential space in the body of the vermilion, which, if correctly entered, will allow the filler to 


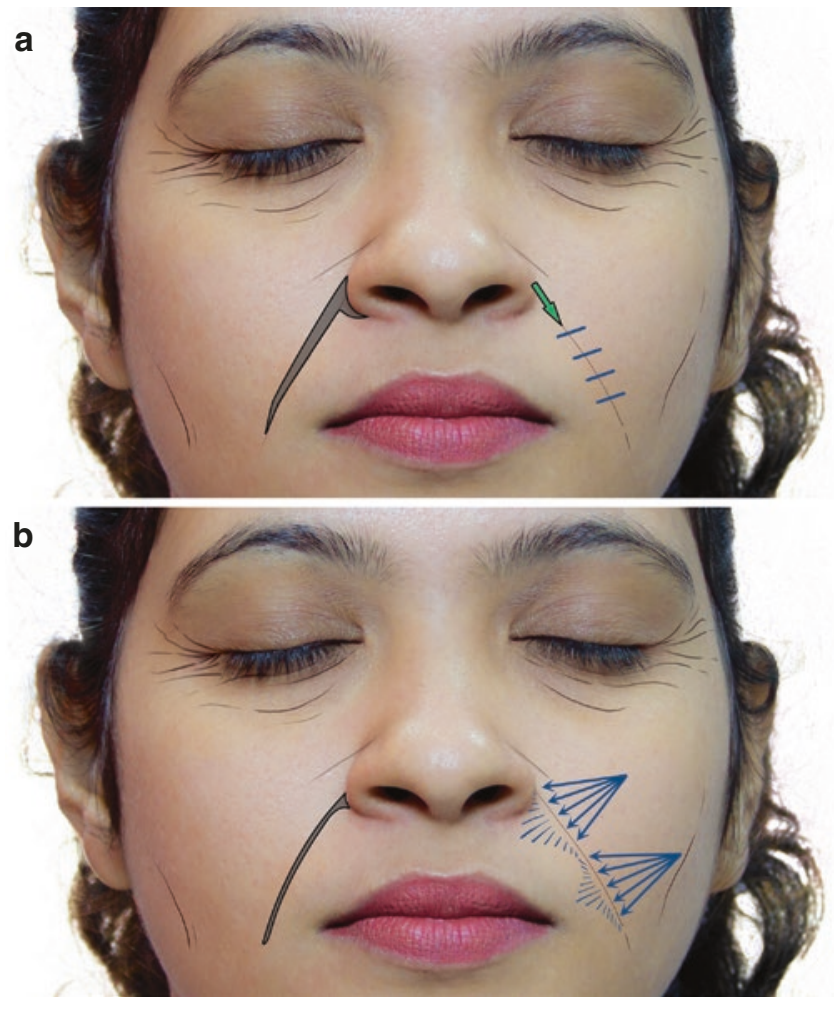

CAssociation of Oral and Maxillofacial Surgeons of India

Fig. 33.14 (a, b) Nasolabial fold injection technique

move within it along the entire lip margin. Dermal fillers injected in the body of the lips can augment, rejuvenate and improve the symmetry of the lips. Philtral columns can get flattened with age. These can be accentuated by injecting along the border of the vermilion and philtral region to give a more prominent philtrum and cupids bow with eversion of the lip. The philtrum may be pinched after injection to accentuate the ridges. Injections are generally placed superficially in to the subcutaneous plane. Massaging or a gentle rub after injection helps to distribute the filler evenly. Injection may be performed in an anterograde fashion, from lateral to medial, and the filler can be tracked along the vermillion.

(d) Tear Trough Deformity (Fig. 33.16): Tear Trough is usually referred to as the crease at the medial segment of the inferior orbital region. As ageing occurs, the infraorbital rim becomes more skeletonised and depressed. To correct this sunken appearance, HA may be injected into the semicircular depression under the eyes. Normally a 30 -gauge needle, $2.5 \mathrm{~cm}$ long, is used to inject in the dermal layer of the lower eyelid to avoid bruising, as this area is highly vascularised. The needle is then inserted upwards at an angle, till it reaches the top of the orbital rim. The finger of the opposite hand may be used to direct the needle by positioning it at this point. The tip of the needle must touch the bone and its precise location must be verified prior to injection. The filler is injected slowly and deeply into this area. Massaging may be done at the injected area to avoid irregularities. If the HA is deposited too deep, a "Tyndall effect" [16] may be observed. Hyaluronic Acid can occasionally increase fluid retention around the periocular area, and lead to infraorbital swelling, edema or discolouration in the medial portion of the orbicularis muscle. If this occurs, subcutaneous hyaluronidase injections may lyse the Hyaluronic Acid and reduce the swelling.

(e) Injection technique to increase the cheek volume (Fig. 33.17): In some patients, fat loss or volume deficit can cause cheek hollowing. The loss of buccal pad of fat causes wrinkled cheeks, exaggeration of nasolabial folds and jowling of the skin at the lower border of the mandible. The submalar region (below the zygomatic arch) and buccal region (lateral to the nasolabial fold) are areas that need attention. The injection technique should be administered in a grid or fanning pattern. The injections must be administered at the dermal-subcutaneous plane. Massaging after injection can help smoothen irregularities.

\subsubsection{Contraindication [22]}

Some of the most common conditions to be avoided for fillers include:

- Scarring and collagen/connective tissue disorders

- Diabetes

- Infections-e.g.: Viral Herpes

- Coagulation problems

- Pregnant or Lactating women

- Psychological conditions

\subsection{Conclusion}

Botulinum Toxin Type A and Hyaluronic acid dermal fillers are very safe and effective under a trained physician or surgeon for therapeutic and cosmetic use. Wrinkles especially those which are located in the face and some asymmetries, mainly caused or worsened by the repeated contraction of facial muscles and ageing process can be effectively treated by these methods.

Proper knowledge of the anatomy of facial muscles and proper techniques are important to achieve predictable results and avoid complications. Informed consent for the procedure must be obtained from the patient after explaining the risks and the outcome, before commencing the treatment. Though Botulinum toxin and dermal Fillers give temporary results, they are safe and very effective in achieving aesthetic outcome.

Disclosure Author has no financial conflicts to disclose. 
a

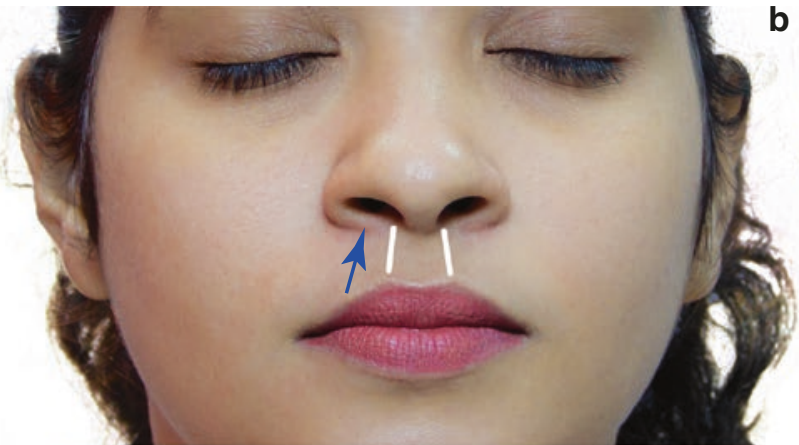

C

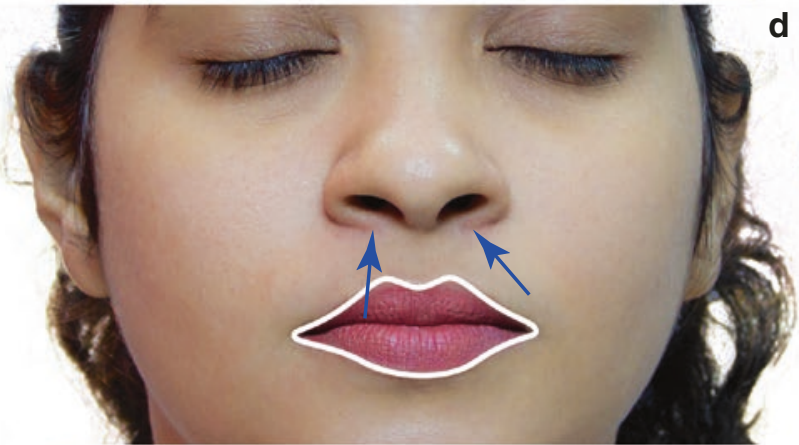

e

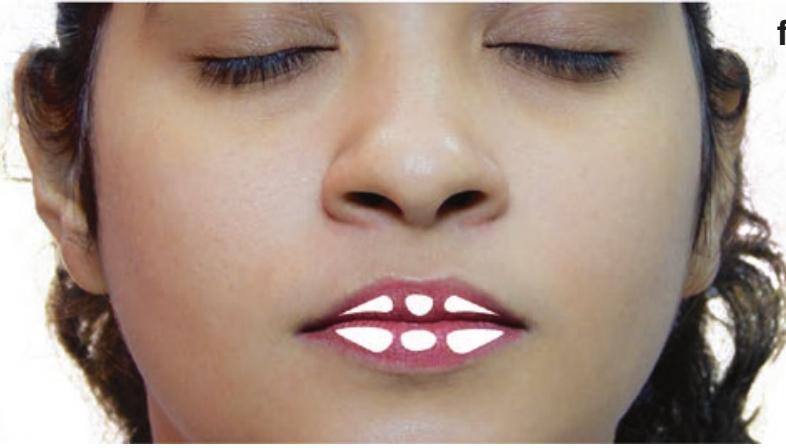

CAssociation of Oral and Maxillofacial Surgeons of India b
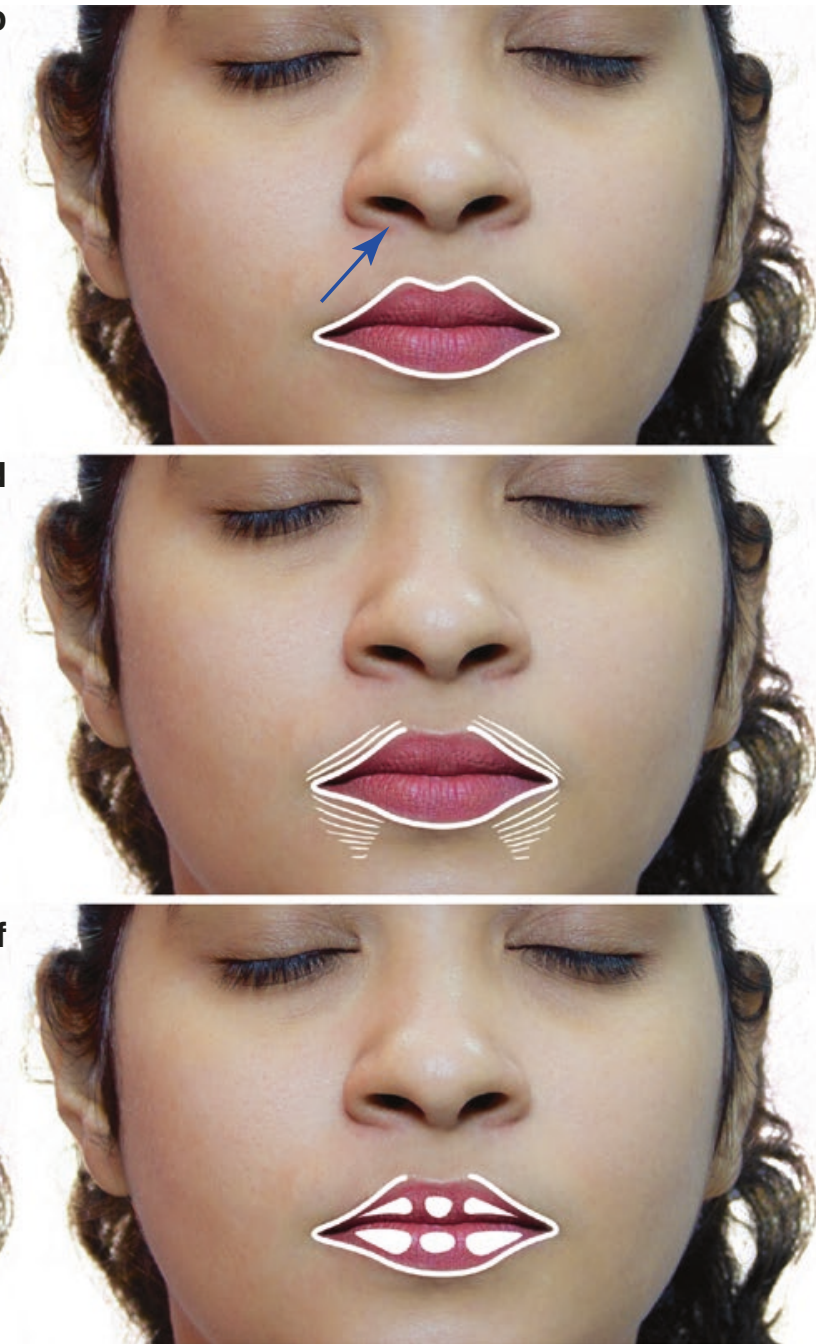

Fig. 33.15 Injection technique for philtrum, lip line and the body of the lip. (a) anterograde filling (b) retrograde filling (c) both anterograde and retrograde filling (d) antero retrograde with fanning if necessary (e) depot and serial puncture filling (f) anterograde retrograde serial and depot filling

Pre periosteal filler along orbital rim

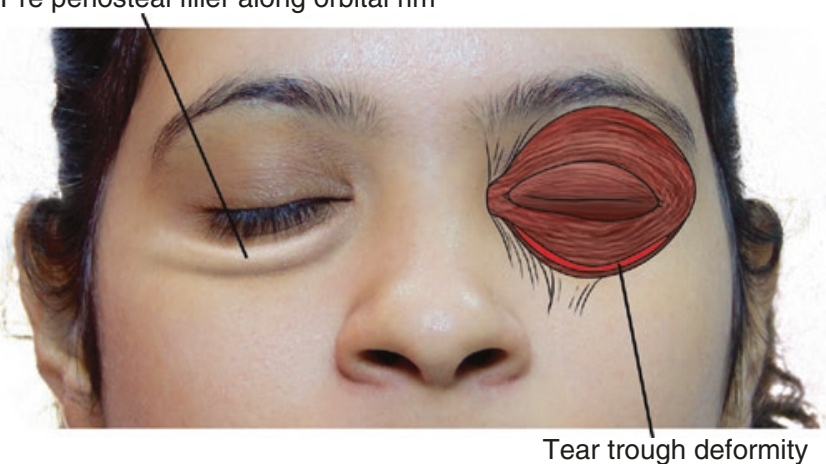

CAssociation of Oral and Maxillofacial Surgeons of India

Fig. 33.16 Tear trough deformity

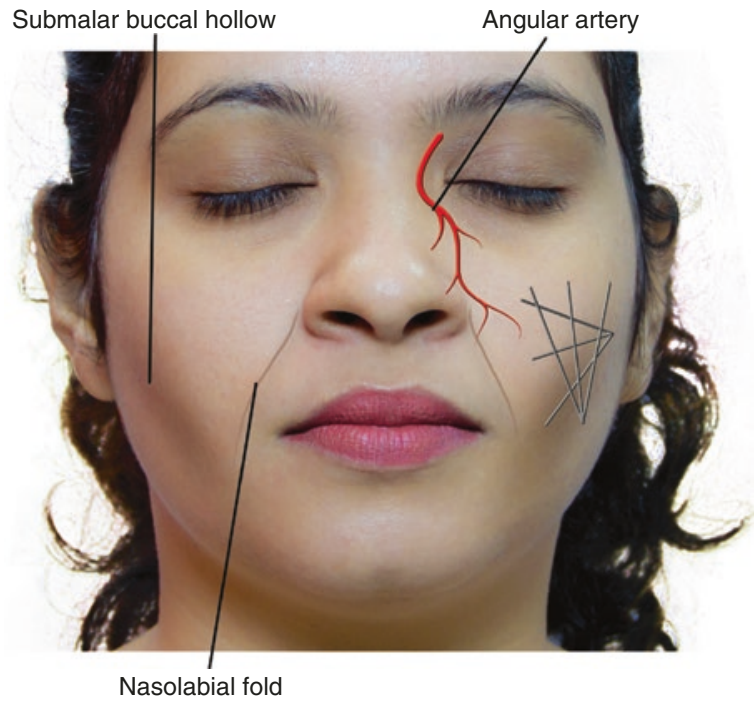

CAssociation of Oral and Maxillofacial Surgeons of India

Fig. 33.17 Injection technique for hollowing cheeks 


\section{Case Scenarios}

Case 1 (Fig. 33.18a,b,c)

A 43-year-old female complaining of excessive tooth and gingival exposure on smiling. Clinical features (Fig. 33.18a): excessive gingival show on smiling normal lip length and normal size of the tooth. Treatment Plan (Fig. 33.18b1, b2, b3 and b4): locating the levator labii superioris muscle and injecting Botulinum toxin Type A with a dose of $5 \mathrm{U}$ on both the sides. The injection point is located at the junction between lip and the ala of the nose. Post-operative findings (Fig. 33.18c): no gingival show on smiling.
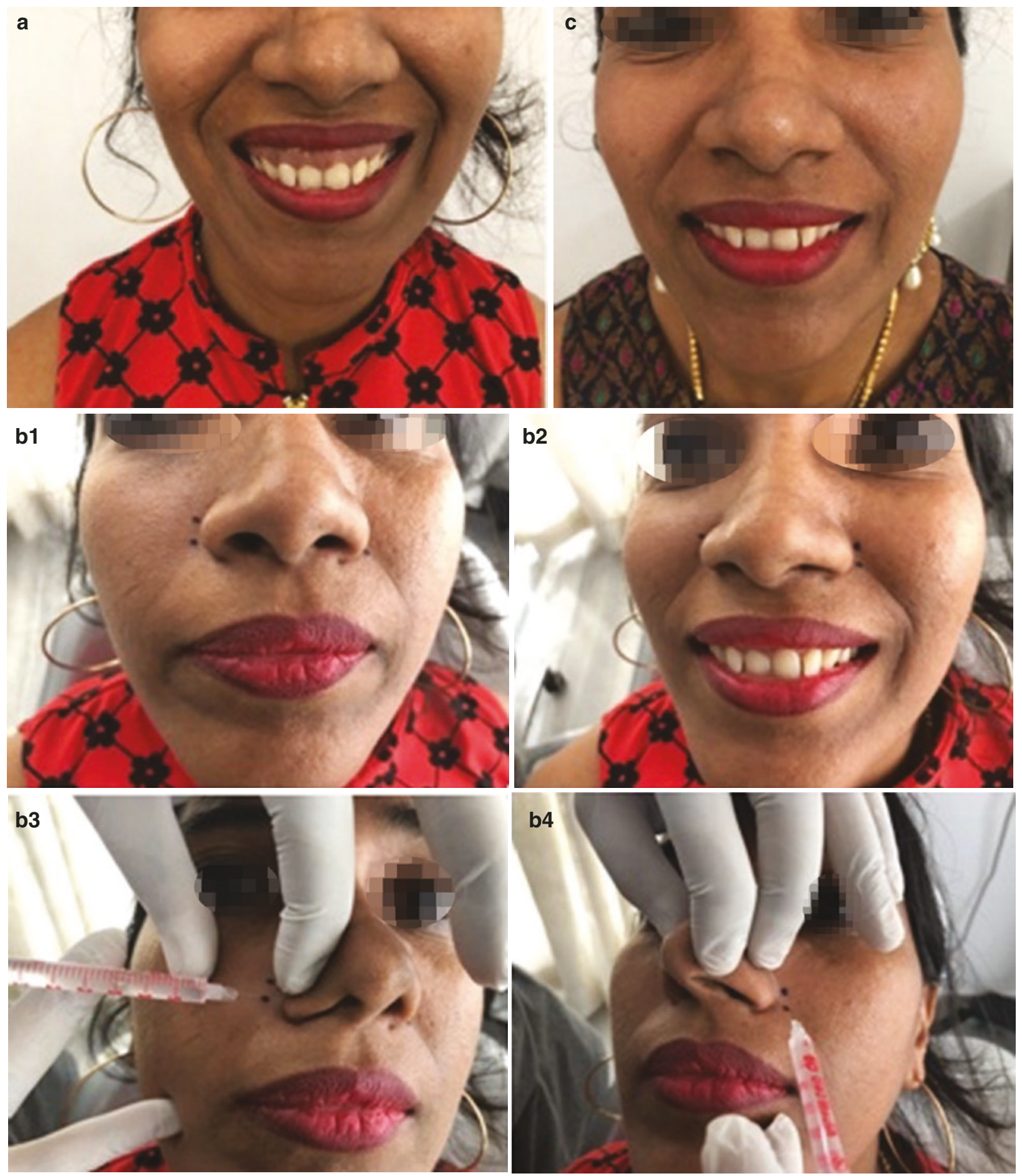

Fig. 33.18 (a) Clinical features with excessive Gingival show. (b1, b2, b3, b4) Intraoperative. (c) Postoperative, absence of Gingival show 

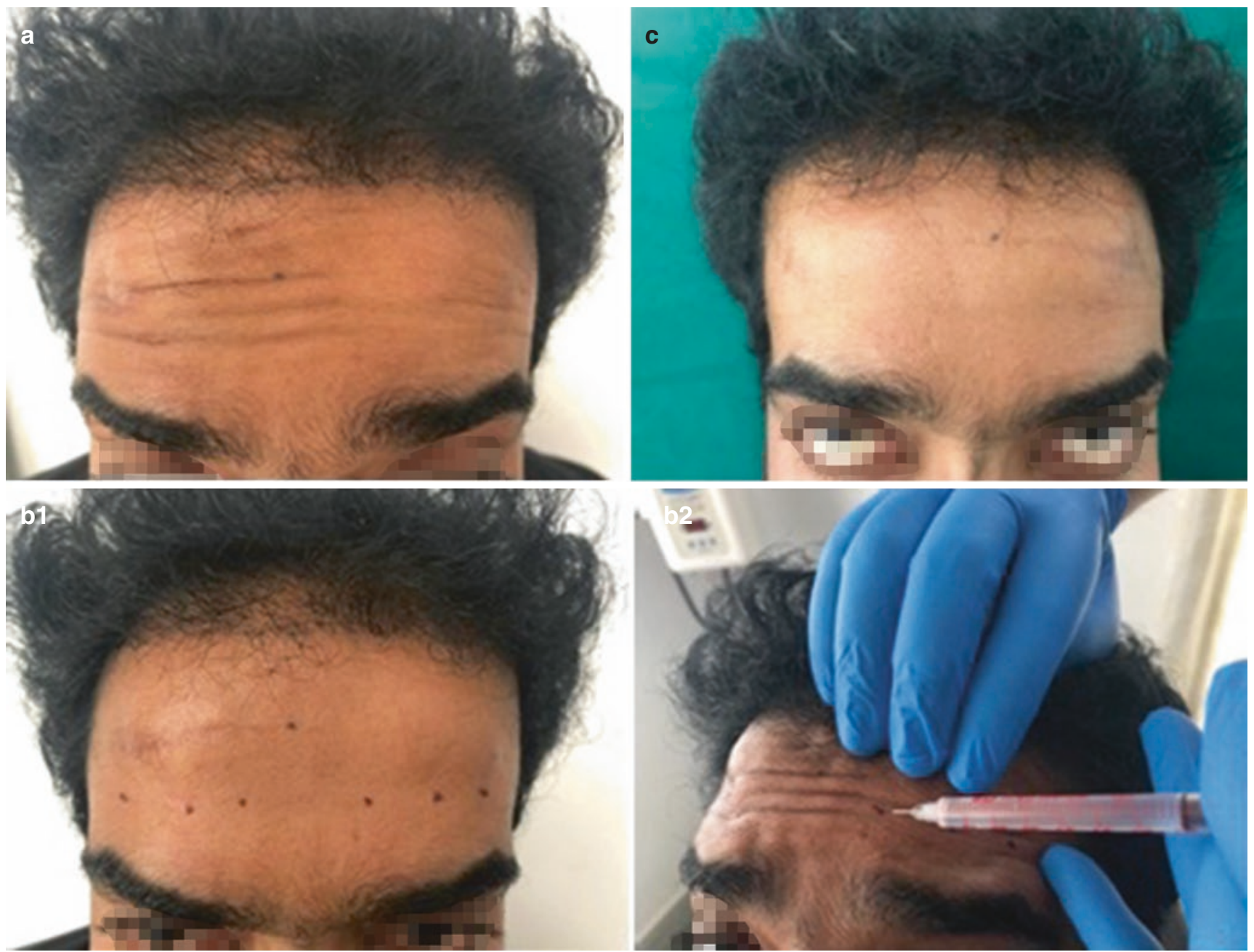

CAssociation of Oral and Maxillofacial Surgeons of India

Fig. 33.19 (a) Clinical feature with forehead wrinkling. (b1, b2) Intraoperative. (c) Post-operative, absence of Wrinkling

\section{Case 2 (Fig. 33.19a,b,c)}

A 47-year-old male, complaining of excessive wrinkling in the forehead on looking upwards and frowning with ageing appearance. Clinical features (Fig. 33.19a): wrinkling and folds found on the forehead on upward starring and frowning. Treatment Plan (Fig. 33.19b1, b2): locating the frontalis muscle and injecting Botulinum toxin Type A with a dose of $5 \mathrm{U}$ on both the sides at 3 different points marked and above $1 \mathrm{~cm}$ from the supraorbital margin. The injection point is located midway between supraorbital margin and frontal hairline. Post-operative findings (Fig. 33.19c): absence of wrinkling.

\section{References}

1. Baran R, Maibach HI. DorisHexel Textbook of cosmetic dermatology. 5th edn; Chap 1,50,51-Skin size and Parameters, Botulinum Toxin, Soft tissue Augmentation Chap; Pg - 3,459,473.
2. Shuster S, Black MM, McVitie E. The influence of age and sex on skin thickness, skin collagen and density. $\mathrm{Br} \mathrm{J}$ Dermatol. 1975;93:639-43.

3. Tsukahara K, Hotta M, Osanai O, et al. Gender-dependent differences in degree of facial wrinkles. Skin Res Technol. 2013;19(1):e65-71.

4. Ezure T, Yagi E, Kunizawa N, et al. Comparison of sagging at the cheek and lower eyelid between male and female faces. Skin Res Technol. 2011;17(4):510-5.

5. Gerhardt LC, Strassle V, Lenz A, et al. Influence of epidermal hydration on the friction of human skin against textiles. J R Soc Interface. 2008;5:1317-28.

6. Carruthers JDA, Carruthers JA. Treatment of glabellar frown lines with $\mathrm{C}$ botulinum-A exotoxin. J Dermatol Surg Oncol. 1992;18:17-21.

7. Dover N, Barash JR, Hill KK, Xie G, Arnon SS. Molecular characterization of a novel botulinum neurotoxin type $\mathrm{H}$ gene. J Infect Dis. 2014;209:192-202.

8. Lebeda FJ, Hack DC, Gentry MK. Theoretical analyses of the functional regions of the heavy chain of botulinum neurotoxin. In: Jankovic J, Hallet M, editors. Therapy with botulinum toxin. New York: Marcel Dekker; 1994. p. 51-61.

9. Hexsel D, Hexsel CL, Bohn J. Long, mid, and short term effects of botulinum toxin on the musculature. In: Hexsel D, Almeida AT, 
editors. Cosmetic use of botulinum toxin. Porto Alegre: AGE; 2002 p. $99-103$.

10. Wollina U, Konrad H. Am J Clin Dermatol. 2005;6(3):141-50.

11. Ascher B, Talarico S, Cassuto D, Escobar S, Hexsel D, Jaén P, et al. International consensus recommendations on the aesthetic usage of botulinum toxin type A (Speywood Unit) — part II: wrinkles on the middle and lower face, neck and chest. J Eur Acad Dermatol Venereol. 2010;24(11):1285-95.

12. Carruthers A. Botulinum toxin type A: history and current cosmetic use in the upper face. Dis Mon. 2002;48:299-322.

13. Hexsel D, Mazzuco R, Zechmeister M, Hexsel CL. Complications and adverse effects: diagnosis and treatment. In: Hexsel D, Almeida AT, editors. Cosmetic use of botulinum toxin. Porto Alegre: AGE; 2002. p. 233-9.

14. Benedetto AV. The cosmetic uses of botulinum toxin type A. Int J Dermatol. 1999;38:641-55.

15. Lorenc ZP, Smith S, Nestor M, Nelson D, Moradi A. Understanding the functional anatomy of the frontalis and glabellar complex for optimal aesthetic botulinum toxin type A therapy. Aesthet Plast Surg. 2013;37(5):975-83.

16. Kontis TC, Lacombe VG. Cosmetic injection technique. New York: Thieme; 2013. p. 23-4.

17. Klein AW. Complications with the use of botulinum toxin. Dermatol Clin. 2004;22(2):197-205.
18. Narins RS, et al. A randomized double-blind multicenter comparison of the efficacy and tolerability of Restylane versus Zyplast for the correction of nasolabial folds. Dermatol Surg. 2003;29(6): 588-95.

19. Donofrio L. Fat distribution: a morphologic study of the aging face. Dermatol Surg. 2000;26:1107-12.

20. Guttman C. A generation speaks: dermatology answers growing desire to fight aging skin. Dermatology Times, pp. 56-60; 2004.

21. Guttman C. Advances in anti-aging: new techniques technology should match demand. Dermatology Times; 2004.

22. Burgers CM. Cosmetic dermatology, 2005; Chapter 6-Soft tissue Augmentation; Pg 103.

23. Glogau R, Narins R, Weiss R. Advances in cosmetic procedures. In Fall clinical dermatology conference supplement proceedings. Supplement to skin and aging, pp. 20-27; 2004.

24. Bisaccia D, Scarborough D. The esthetic correction of the aging mouth. Cosmet Dermatol. 1992;11:8-11.

25. Elson M. Soft tissue augmentation techniques: update on available materials. Cosmet Dermatol. 1999:13-5.

26. Lemperle G, Romano JJ, Busso M. Soft tissue augmentation with Artecoll: 10-year history indications techniques and complications. Dermatol Surg. 2003;29(6):573-87.

Open Access This chapter is licensed under the terms of the Creative Commons Attribution 4.0 International License (http://creativecommons. org/licenses/by/4.0/), which permits use, sharing, adaptation, distribution and reproduction in any medium or format, as long as you give appropriate credit to the original author(s) and the source, provide a link to the Creative Commons license and indicate if changes were made.

The images or other third party material in this chapter are included in the chapter's Creative Commons license, unless indicated otherwise in a credit line to the material. If material is not included in the chapter's Creative Commons license and your intended use is not permitted by statutory regulation or exceeds the permitted use, you will need to obtain permission directly from the copyright holder. 